\title{
Angioleiomyoma affecting the lips: Report of 3 cases and review of the literature
}

\author{
Luiz-Alcino Gueiros ${ }^{1}$, Mário-José Romañach ${ }^{1}$, Ana-Maria Pires-Soubhia ${ }^{2}$, Fábio-Ramôa Pires ${ }^{3}$, Oslei Paes- \\ de-Almeida ${ }^{1}$, Pablo-Agustin Vargas ${ }^{1}$
}

\footnotetext{
${ }^{1}$ Department of Oral Diagnosis - Laboratory of Oral Pathology. Piracicaba Dental School - University of Campinas

${ }^{2}$ Department of Pathology and Clinical Propedeutics - Laboratory of Oral Pathology. Araçatuba Dental School - Júlio Mesquista State University

${ }^{3}$ Stomatology, Estácio de Sá University
}

\author{
Correspondence: \\ Department of Oral Diagnosis \\ Oral Pathology Section \\ Piracicaba Dental School \\ State University of Campinas \\ P.O. Box 52 - 13414-903, Piracicaba, SP, Brazil \\ pavargas@fop.unicamp.br
}

Received: $27 / 02 / 2010$

Accepted: 25/03/2010

\begin{abstract}
Gueiros LA, Romañach MJ, Pires-Soubhia AM, Pires FR, Paes-deAlmeida O, Vargas PA. Angioleiomyoma affecting the lips: Report of 3 cases and review of the literature. Med Oral Patol Oral Cir Bucal. 2011 Jul 1;16 (4):e482-7.

http://www.medicinaoral.com/medoralfree01/v16i4/medoralv16i4p482.pdf
\end{abstract}

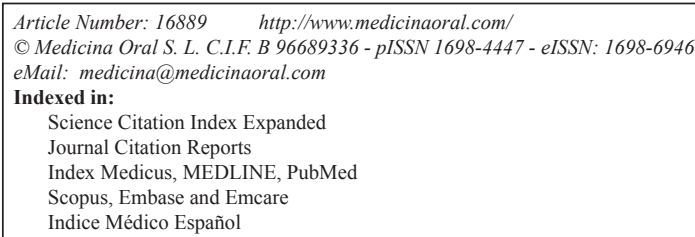

Indice Médico Español

\begin{abstract}
Angioleiomyoma is an uncommon benign soft tissue tumor usually found in the lower extremities and rarely observed in oral tissues. It is microscopically characterized as a proliferation of smooth muscle cells intermingled with abundant vascular channels. Oral angioleiomyomas affect mostly the lips, palate, buccal mucosa and tongue, and appears as a submucosal painless nodule. Upper lip is seldom affected and only few cases have been reported. We report three additional cases of angioleiomyoma affecting the lips of elderly patients. All lesions were asymptomatic and presented as submucosal nodules of approximately $1 \mathrm{~cm}$. Microscopic analysis on H\&E sections revealed similar pattern in all cases, showing well-circumscribed and encapsulated tumors characterized by proliferation of smooth muscle cells and large amount of wide vascular spaces of varying sizes. Most tumor cells were immunoreactive for $\alpha$-smooth muscle actin, desmin and HHF-35. CD34 was also positive on the endothelial cells. All patients were surgically treated and no recurrence was observed so far. The oral pathologists and clinicians should consider this entity when assessing nodular lesions on upper lip.
\end{abstract}

Key words: Lip neoplasms, vascular neoplasms, angioleiomyoma.

\section{Introduction}

Leiomyomas are benign smooth muscle tumors that preferably affect the genitals, skin and gastrointestinal tract, being rarely seen in the oral cavity and commonly classified into three microscopic patterns: solid leiomyoma, angioleiomyoma (ALM) and epithelioid leiomyoma (1). ALM is a relatively common neoplasm ac- counting for about $5 \%$ of all benign soft tissue tumours and almost three fourths of all oral leiomyomas $(1,2)$. Approximately 150 cases of oral ALM have been reported up to now, being frequently identified as a bluish submucosal painless nodule affecting the lips, palate, buccal mucosa, and tongue, presenting important clinical differential diagnosis (1). 
Microscopically, ALM consists in a well-circumscribed lesion presenting vascular spaces with varied size and thick muscle walls, containing concentrically arranged smooth muscle cells within the muscular walls and interspersed with collagen fibers between vessels (3). The smooth muscle origin can be confirmed through a strong cytoplasmic staining pattern of all tumor cells by antibodies directed against smooth muscle actin (3). According to the dominant microscopic pattern some authors additionally classify oral ALM as solid/capillary, venous, and cavernous. The latter is characterized by the majority of large vascular spaces and it is the most uncommon subtype (3). The aims of this paper are to report three cases of ALM affecting the lips and to discuss its clinicopathological and immunohistochemical features.

\section{Case Reports}

\section{Case 1}

A 54 year-old male was referred for evaluation complaining of an asymptomatic lower lip nodule with 6 months of evolution (Fig. 1). He was HIV positive without any other remarkable disease. On physical examination it could be noted a tiny painless submucosal nodule on the right portion of the lower lip, fibrous on palpation and measuring $1 \times 1 \mathrm{~cm}$. Under the clinical differential diagnosis of deep-seated mucocele, hemangioma, fibrous hyperplasia and pleomorphic adenoma, the patient was submitted to an excisional biopsy after local anesthesia. The specimen was processed and histopathological examination revealed a well-circumscribed smooth muscle proliferation (Fig. 2A1). The lesion presented a uniform pattern composed mostly of spindle-shaped cells and blood vessels (Fig. 2A2 and 2A3). A diagnosis of angioleiomyoma was rendered and the patient presented no further complications following two years of follow up.

Case 2

A 66 year-old male presented with an asymptomatic well-defined fibrous nodule in the central portion of the upper lip lasting 19 years. Medical history was noncontributory and an excisional biopsy was performed. Histopathological examination revealed a multinodular mass full of large vascular spaces. Stroma was composed of spindled cells and small blood vessels (Fig. 2B1 and 2B3). A final diagnosis of angioleiomyoma was rendered and the patient undertook periodic evaluations and failed to show recurrence after 1 year following surgery.

Case 3

A 53 year-old male presented with a slightly bluish painless fibrous nodule with a smooth surface, measuring $0.8 \times 0.5 \times 0.5 \mathrm{~cm}$ in the upper lip, lasting 5 months. Medical history was non-contributory. Clinical diagnosis included fibrous hyperplasia, hemangioma,

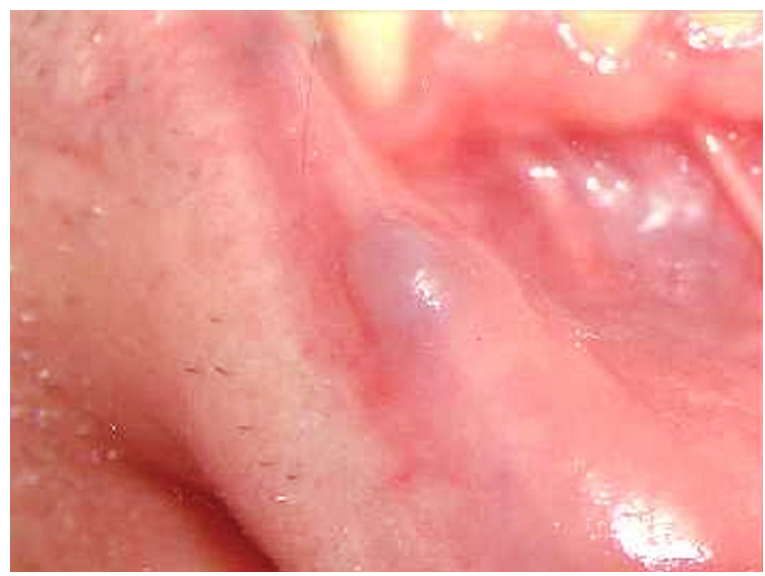

Fig. 1. A small well-defined mass of the lower lip. Note the bluish aspect of the tumor (case 1).

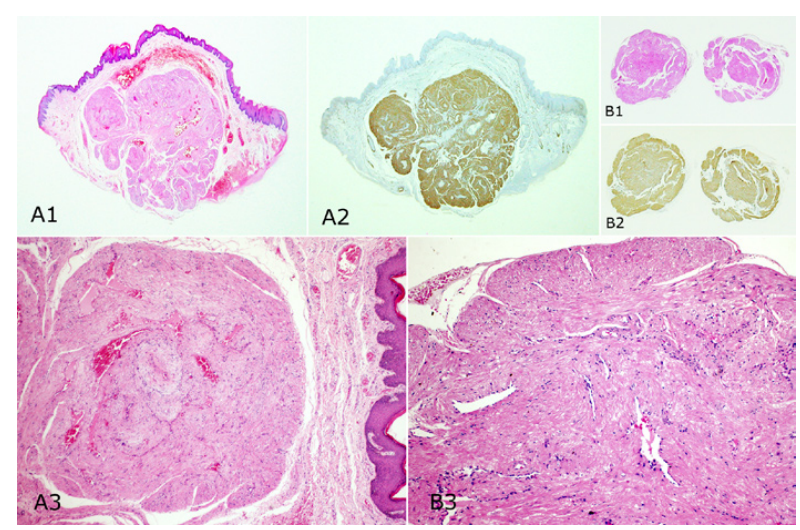

Fig. 2. A1-Well-defined tumor with intense hemorrhage which assumes a venous pattern intermingled with solid areas (case 1) (HE, slide view). A2 - Smooth muscle actin positivity of the tumor cells (case 1) (Immunoperoxidase, slide view). A3 - Close relation of the tumor to the surface. A solid/venous pattern is observed (case 1) (HE, OM 50x). B1 - Tiny tumor with solid aspect (case 2) (HE, slide view). B2 - Smooth muscle actin staining all tumor cells (case 2) (Immunoperoxidase, slide view). B3 - Solid tumor of muscular cells with lacking vascular spaces (case 2) (HE, OM 100x).

pleomorphic adenoma and canalicular adenoma, and the lesion was submitted to an excisional biopsy. Gross pathological examination demonstrated a white nodule measuring $0.6 \times 0.5 \times 0.4 \mathrm{~cm}$ and after sectioning dark brownish areas could be seen in the inner portion (Fig. 3A). Histological examination revealed a multilobulated well-circumscribed lesion (Fig. 3B and 3C). The tumor presented bands of smooth muscle cells surrounding multiple vascular spaces of varying sizes. The spindleshaped cells showed elongated blunt-ended nuclei and eosinophilic cytoplasm forming smooth muscle bundles showing interlacing pattern with collagen fibers between dilated and slit-like vascular spaces (Fig. 3D). Final diagnosis was angioleiomyoma and no local recurrence has been detected after 6 months of follow up. 


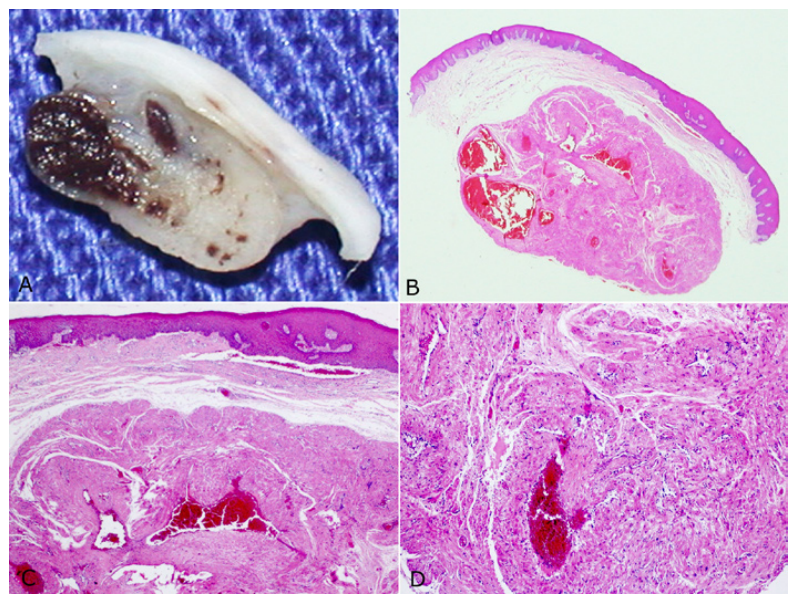

Fig. 3. A-Macroscopic view of the surgical specimen highlighting dark brown areas corresponding to ample vascular spaces (case 3) (Macroscopy). B - Well-defined tumor plenty of large vascular spaces assuming a cavernous pattern (case 3) (HE, slide view). C - Close relation to the surface epithelium lacking a capsule (case 3) (HE, original magnification - OM x25). D - Vascular space surrounded by smooth muscle fibers of the tumor stroma (case 3) (HE, OM x 50).

\section{Immunohistochemical Findings}

Immunohistochemical analysis was performed after confirmation of diagnosis and included desmin (D33, dilution 1:1000, Dako Corporation, Carpinteria, CA), alpha-smooth muscle actin (1A4, dilution 1:400, Dako Corporation), muscle specific actin (HHF35, dilution 1:800, Dako Corporation), S-100 (Polyclonal, dilution 1:12000, Dako Corporation), CD34 (QBEnd10, dilution 1:50, Dako Corporation) and D2-40 (D2-40, dilution 1:200, Dako Corporation). Briefly, the slides were hydrated, and subjected to microwave antigen retrieval in sodium citrate solution ( $\mathrm{pH} \mathrm{6}$ ). Next, the sections were treated with $3 \% \mathrm{H} 2 \mathrm{O} 2$ and incubated overnight with the primary antibody. This was followed by secondary antibodies conjugated with streptavidin-biotin-peroxidase (Strept ABComplex/HRP Duet, Mouse/Rabbit, DAKO, Denmark), which were visualized with diaminobenzidine chromogen counterstained with Carazzi's haematoxylin. The spindle-shaped cells were immunoreactive for alpha-smooth muscle actin (Fig. 2A2, 2B2 and 4A), muscle specific actin (Fig. 4B), and desmin (Fig. 4C). The endothelial cells along the walls of the prominent vascular channels were immunoreactive for CD 34 (Fig. 4D).

\section{Discussion}

Angioleiomyoma (ALM) is a well-described tumor characterized by neoplastic proliferation of mature smooth muscle cells associated with variable amount of blood vessels. It usually presents as a painful nodule affecting the extremities, albeit oral lesions seems to be asymptomatic. All three patients of the current

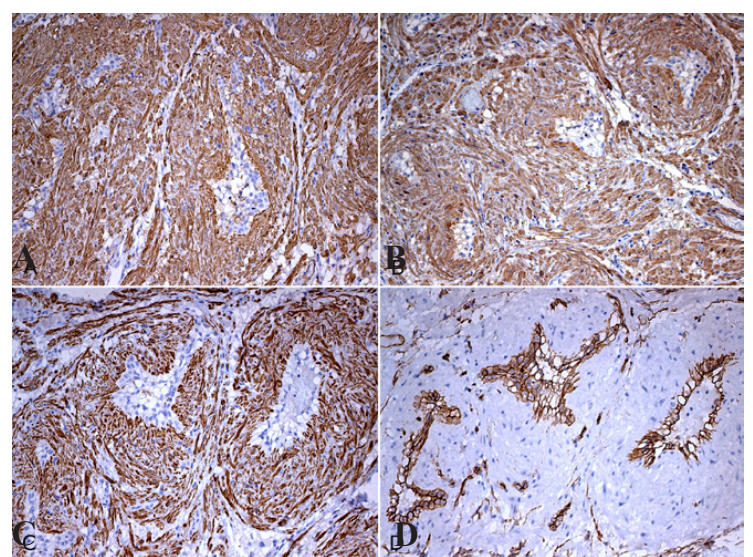

Fig. 4. Immunohistochemical expression of smooth muscle actin (A), HHF-35 (B) and D33 (desmin) (C) in tumor cells confirming the muscle origin (case 3) (Immunoperoxidase, OM 200x). D - CD34 staining the goblet-shaped endothelial cells (case 3) (Immunoperoxidase, OM 200x). series were male, yielding a male prevalence similar to previously reported (1). Patients' age ranged from 53 to 66 years, with a mean age of 57,7 years. All lesions were described as small nodules, which were fibrous on palpation. To characterize the clinical features of oral ALM, cases described in our study were joined to additional 50 cases of labial ALM, retrieved from the literature (Table 1).

The age of 36 of 53 patients with labial angioleiomyoma could be retrieved from the literature, and the mean age was 47,4 years. Similarly to a previous report, fifth and sixth decades represented the greatest cluster of patients (1). Nevertheless, Gaitan-Cepeda et al. (18) reported a larger distribution in younger patients, with the highest prevalence being observed in the fourth and fifth decades of life. Interestingly, the mean age of our three cases was considerably higher than the mean age of all cases of angioleiomyoma. Considering gender, $62,5 \%$ of the cases affected males, yielding a male to female ratio of 1,67:1. In fact, a similar gender distribution yielding male predilection has been previously reported elsewhere $(1,17)$.

Labial masses are usually found in clinical setting but ALM are not commonly observed and consequently their clinical suspicion is hardly considered when a submucous nodule is observed on the lips. Fibrous hyperplasia, salivary retention cyst and salivary gland tumors are much more likely to occur in the upper lip, which routinely makes clinical diagnosis limited. On the lower lip, mucocele, hemangioma, fibrous hyperplasia and pyogenic granulomas are much more likely to occur. Nevertheless, surgical excision is the most likely treatment to these labial lesions, including ALM, and recur- 
Table 1. Clinical data of labial angioleiomyomas reported in the English-language literature from 1969 to date.

\begin{tabular}{|c|c|c|c|c|c|c|c|}
\hline Authors & $N^{\circ}$ Cases & Gender & Age (years) & Site (Lip) & Size (mm) & Symptoms & Duration \\
\hline \multirow{2}{*}{ McGowan \& Jones (1969) (4) } & 1 & $\mathrm{M}$ & UN & Lower & 10 & Up to 14 years & UN \\
\hline & 2 & $\mathrm{~F}$ & $\mathrm{UN}$ & Upper & 10 & Up to 14 years & $\mathrm{UN}$ \\
\hline Gutmann et al (1974) (5) & 3 & $\mathrm{~F}$ & 44 & Lower & 5 & $\mathrm{UN}$ & $\mathrm{UN}$ \\
\hline Giles \& Gosney (1982) (6) & 4 & $\mathrm{M}$ & 46 & Upper & 10 & UN & 4 years \\
\hline Hashisuga et al (1984 (2) & $5-15$ & $\mathrm{UN}$ & $\mathrm{UN}$ & Lip & UN & $\mathrm{UN}$ & UN \\
\hline Epivatianos et al (1985) (7) & 16 & $\mathrm{M}$ & $\mathrm{UN}$ & Upper & 10 & UN & 4 months \\
\hline \multirow{2}{*}{ Esguep \& Sola (1986) (8) } & 17 & $\mathrm{M}$ & 47 & Lower & $15 \times 10$ & $\mathrm{UN}$ & UN \\
\hline & 18 & M & 50 & Upper & $13 \times 11$ & UN & UN \\
\hline Terui et al (1987) (9) & 19 & M & 34 & Lower & 10 & UN & 8 years \\
\hline Kawakami et al (1987) (10) & 20 & M & 33 & Lip & $\mathrm{UN}$ & $\mathrm{UN}$ & $\mathrm{UN}$ \\
\hline Candelaria et al (1988) (11) & 21 & $\mathrm{UN}$ & $\mathrm{UN}$ & Upper & UN & $\mathrm{UN}$ & UN \\
\hline Maeda et al (1989) (12) & 22 & $\mathrm{M}$ & 37 & Upper & $7 \times 8$ & Painless & UN \\
\hline \multirow{3}{*}{ Baden et al (1994) (13) } & 23 & \multirow{3}{*}{\multicolumn{6}{|c|}{$\mathrm{UN}$}} \\
\hline & 24 & & & & & & \\
\hline & 25 & & & & & & \\
\hline Anastassov et al (1995) (14) & 26 & $\mathrm{M}$ & 51 & Upper & 15 & $\mathrm{UN}$ & 1 year \\
\hline Reyes Santías et al (1998) (15) & 27 & $\mathrm{~F}$ & 74 & Lower & $\mathrm{UN}$ & $\mathrm{UN}$ & $\mathrm{UN}$ \\
\hline Toida et al (2000) (16) & 28 & $\mathrm{M}$ & 10 & Lower & $20 \times 15$ & Painful & Several years \\
\hline \multirow{5}{*}{$\begin{array}{l}\text { Brooks et al } \\
(2002)(1)\end{array}$} & 29 & $\mathrm{M}$ & 14 & Lower & $3 \times 3$ & UN & "years" \\
\hline & 30 & $\mathrm{M}$ & 18 & Lower & $4 \times 5$ & None & 1 month \\
\hline & 31 & $\mathrm{M}$ & 59 & Lower & $\mathrm{UN}$ & $\mathrm{UN}$ & 4 months \\
\hline & 32 & $\mathrm{~F}$ & 44 & Upper & $2 \times 2$ & UN & 18 months \\
\hline & 33 & $\mathrm{~F}$ & $\mathrm{UN}$ & Lower & $3 \times 8 \times 9$ & UN & UN \\
\hline \multirow{3}{*}{ Wang et al (2004) (17) } & 34 & $\mathrm{~F}$ & 52 & Upper & 6 & UN & $\mathrm{UN}$ \\
\hline & 35 & $\mathrm{~F}$ & 65 & Upper & 7 & UN & $\mathrm{UN}$ \\
\hline & 36 & $\mathrm{~F}$ & 67 & Lower & 6 & UN & $\mathrm{UN}$ \\
\hline \multirow{12}{*}{ Ide et al (2008) (3) } & 37 & $\mathrm{M}$ & 55 & Upper & 10 & \multirow{12}{*}{ UN } & \multirow{12}{*}{ UN } \\
\hline & 38 & $\mathrm{M}$ & 42 & Lower & 20 & & \\
\hline & 39 & $\mathrm{M}$ & 57 & Lower & 10 & & \\
\hline & 40 & $\mathrm{M}$ & 48 & Lower & 16 & & \\
\hline & 41 & $\mathrm{~F}$ & 67 & Upper & 15 & & \\
\hline & 42 & $\mathrm{M}$ & 44 & Upper & 18 & & \\
\hline & 43 & $\mathrm{~F}$ & 73 & Upper & 22 & & \\
\hline & 44 & $\mathrm{~F}$ & 43 & Lower & 4 & & \\
\hline & 45 & $\mathrm{M}$ & 30 & Lower & 8 & & \\
\hline & 46 & $\mathrm{M}$ & 40 & Lower & 7 & & \\
\hline & 47 & $\mathrm{M}$ & 60 & Lower & 9 & & \\
\hline & 48 & $\mathrm{M}$ & 57 & Upper & 11 & & \\
\hline \multirow{3}{*}{$\begin{array}{l}\text { Gaitan Cepeda et al (2008) } \\
\text { (18) }\end{array}$} & 49 & $\mathrm{~F}$ & 43 & Lower & $7 \times 5$ & Painless & 9 months \\
\hline & 50 & $\mathrm{~F}$ & 36 & Upper & $15 \times 10$ & Painless & 7 years \\
\hline & 51 & $\mathrm{M}$ & 48 & Upper & $17 \times 10$ & UN & UN \\
\hline Chang Kessler (2008) (19) & 52 & $\mathrm{~F}$ & 45 & Upper & UN & UN & $\mathrm{UN}$ \\
\hline \multirow{3}{*}{$\begin{array}{c}\text { Current } \\
\text { (2010) }\end{array}$} & 53 & M & 53 & Upper & $8 \times 8$ & Painless & 5 months \\
\hline & 52 & $\mathrm{~F}$ & 54 & Lower & $10 \times 10$ & Painless & 6 months \\
\hline & 53 & $\mathrm{M}$ & 66 & Upper & UN & Painless & 19 years \\
\hline
\end{tabular}

$\mathrm{UN}$ - unavailable. 
rences are not expected. Bleeding is seldom observed when removing labial ALM despite the prominent vascular component, possibly because the lesion is usually well-circumscribed and well-demarcated (1).

Macroscopic aspects of ALM can be highly suggestive. Evaluation of case 3 revealed a whitish mass of fibroelastic consistency during gross examination and after sectioning dark brownish areas could be observed intermingled with pale fibrous structures. The presence of dark-brown areas in the cut surface is expected in such cases, representing large vascular spaces characteristic of the cavernous pattern $(2,4)$.

ALM can be microscopically subclassified into three distinct patterns: solid, venous or cavernous $(2,20)$. The solid-type is composed of compacted bundles of smooth muscle cells and thin-walled vessels; the venous type shows thick walls of the vascular channels and blending of the vascular musculature with the intervascular muscle bundles. The cavernous-type is characterized by large vascular channels with thin muscular walls, which are difficult to differentiate from intervascular muscle bundles. There can be also a mixture of patterns, leading to biphasic lesions. Matsuyama et al. reviewed 122 ALM and found only 23 mixed cases and only two of these were venous-cavernous type (20). To the best of our knowledge, case 3 is the first case of mixed oral ALM displaying a venous-cavernous pattern.

Also, a great amount of morphological variations have already been described. Areas of recent hemorrhage and deposits of hemossiderin have been described in solid-type tumors. Dense hyalinization of collagen, foci of calcification and areas with mature fat cells may be also part of the tumor stroma $(2,20)$. None of these features were seen in our cases, but some foci of gobletshaped endothelial cells could be observed in the contracted blood vessels, similar to the picture described by Guttmann et al. (5). This feature is rarely described and its endothelial origin can be confirmed through CD34 positive staining (Fig. 4D). The presence of nerve fibers in the capsule have already been described, and cases 1 and 3 showed S-100 immunostaining in the periphery of the tumor (2). Interestingly, case 2 presented with S100 positive cells intermingled with tumor stroma, what can possibly represent a cross reaction because of the polyclonality of S100 antibody. Despite of the presence of S100 positive nerve fibers on the periphery of cases 1 and 3 , no symptoms were reported.

The immunohistochemical pattern of ALM is well recognized and may in turn be distinguished from other perivascular myoid tumors easier. Strong and diffuse immunopositivity for SMA is observed in this subset of lesions, which include ALM, myopericytoma (MPC), myofibroma and glomus tumor $(3,18)$. Other smooth muscle markers, such as HHF-35, calponin and h-caldesmon, also show similar immunostaining pattern in
ALM and MPC. Nevertheless, desmin is more specific for ALM, and $75 \%$ of the solid-type, $51 \%$ of the venoustype and $18 \%$ of the cavernous type tumors are positive for this marker. Interestingly, the MPC-like portions in the ALM are desmin-negative and thus allow adequate distinction in difficult cases (17). All three cases were $100 \%$ positive for alpha-smooth muscle actin, HHF-35 and desmin (Figs. 4A, 4B and 4C).

Although the classic presentation lacks diagnostic difficulties, some tumors (specially the venous-type) present perivascular concentric arrangement of myoid cells similar to those observed in myopericytoma which may turn the diagnosis somewhat complex (17). Distinction between classic histopathologic presentation of ALM and MPC does not present a diagnostic challenge. Anyhow, approximately $21 \%$ of all ALM may present some MPC-like areas with perivascular concentric smooth muscle cells proliferation, which are desmin-negative. On the other hand, a great proportion $(50 \%)$ of MPC may also present ALM-like areas with variable amount of eosinophilic spindle cells and venous or cavernous pattern (17). It seems important to highlight that perivascular concentric growth of myoid cells cannot be considered the only distinctive aspect of MPC.

In summary, ALM may be considered as a perivascular myoid tumor with some distinctive aspects. As they can be considered rare in the lips, their clinical suspicion is not common. Surgical excision is the adequate treatment and no recurrence is expected. Desmin immunostaining seems to be helpful when morphological aspects are not conclusive.

\section{References}

References with links to Crossref - DOI

1. Brooks JK, Nikitakis NG, Goodman NJ, Levy BA. Clinicopathologic characterization of oral angioleiomyomas. Oral Surg Oral Med Oral Pathol Oral Radiol Endod. 2002;94:221-7.

2. Hachisuga T, Hashimoto H, Enjoji M. Angioleiomyoma. A clinicopathologic reappraisal of 562 cases. Cancer. 1984;54:126-30.

3. Ide F, Mishima K, Yamada H, Saito I, Horie N, Shimoyama T, et al. Perivascular myoid tumors of the oral region: a clinicopathologic reevaluation of 35 cases. J Oral Pathol Med. 2008;37:43-9.

4. McGowan DA, Jones JH. Angioma (vascular leiomyoma) of the oral cavity. Oral Surg Oral Med Oral Pathol. 1969;27:649-52.

5. Gutmann J, Cifuentes C, Balzarini MA, Sobarzo V, Vicuña R. Angiomyoma of the oral cavity. Oral Surg Oral Med Oral Pathol. 1974;38:269-73.

6. Giles AD, Gosney MB. Oral angiomyoma: a case report. Br J Oral Surg. 1982;20:142-6.

7. Epivatianos A, Trigonidis G, Papanayotou P. Vascular leiomyoma of the oral cavity. J Oral Maxillofac Surg. 1985;43:377-82.

8. Esguep A, Solar M. Oral vascular leiomyoma--report of 5 cases and review of the literature. J Oral Med. 1986;41:126-9,133.

9. Terui T, Takahashi M, Tagami H. Angioleiomyoma of the lip. Int J Dermatol. 1987;26:119-20.

10. Kawakami T, Hasegawa H, Chino T. A transmission electron microscopic study of two cases of oral smooth muscle neoplasm. J Oral Maxillofac Surg. 1987;45:551-5.

11. Candelaria LM, Warnock GR, Pankey G. Nonpainful, smoothsurfaced, bluish nodule on the upper lip. J Am Dent Assoc. 1988;117:487-8.

12. Maeda Y, Hirota J, Osaki T, Hayashi K, Sonobe H, Otsuki Y. An- 
giomyoma of the upper lip: report of a case with electron microscopic and immunohistochemical observation. Br J Oral Maxillofac Surg. 1989;27:236-42.

13. Baden E, Doyle JL, Lederman DA. Leiomyoma of the oral cavity: a light microscopic and immunohistochemical study with review of the literature from 1884 to 1992 . Eur J Cancer B Oral Oncol. 1994;30B:1-7.

14. Anastassov GE, Van Damme PA. Angioleiomyoma of the upper lip: report of a case. Int J Oral Maxillofac Surg. 1995;24:301-2.

15. Reyes Santías RM, Suárez Peñaranda JM, Martín Martín C, Abdulkader I, Forteza Vila J. [Smooth muscle tumor of the lower lip. A report of a case of rapid growing and increased mitotic activity]. Acta Otorrinolaringol Esp. 1998;49:495-7.

16. Toida M, Koizumi H, Shimokawa K. Painful angiomyoma of the oral cavity: report of a case and review of the literature. J Oral Maxillofac Surg. 2000;58:450-3.

17. Wang CP, Chang YL, Sheen TS. Vascular leiomyoma of the head and neck. Laryngoscope. 2004;114:661-5.

18. Gaitan Cepeda LA, Quezada Rivera D, Tenorio Rocha F, Leyva Huerta ER, Mendez Sánchez ER. Vascular leiomyoma of the oral cavity. Clinical, histopathological and immunohistochemical characteristics. Presentation of five cases and review of the literature. Med Oral Patol Oral Cir Bucal. 2008;13:E483-8.

19. Chang JY, Kessler HP. Masson trichrome stain helps differentiate myofibroma from smooth muscle lesions in the head and neck region. J Formos Med Assoc. 2008 ; 107:767-73.

20. Matsuyama A, Hisaoka M, Hashimoto H. Angioleiomyoma: a clinicopathologic and immunohistochemical reappraisal with special reference to the correlation with myopericytoma. Hum Pathol. 2007;38:645-51. 